ISSN 0103-9954

\title{
DINÂMICA DA ESTRUTURA DA COMUNIDADE DE LAURÁCEAS NO PERÍODO 1995-2004 EM UMA FLORESTA DE ARAUCÁRIA NO SUL DO ESTADO DO PARANÁ, BRASIL
}

\author{
STRUCTURAL DYNAMICS OF THE LAURACEAE COMMUNITY DURING 1995-2004 IN AN \\ ARAUCARIA FOREST, SOUTHERN PARANÁ STATE, BRAZIL
}

\author{
Geise de Góes Canalez ${ }^{1}$ Ana Paula Dalla Corte ${ }^{2}$ Carlos Roberto Sanquetta ${ }^{3}$ \\ RESUMO
}

\begin{abstract}
Várias espécies da família Lauraceae estão entre as mais comuns na Floresta de Araucária. Elas possuem bom potencial silvicultural e econômico, mas são pouco estudadas. Este trabalho trata das mudanças estruturais no período 1995-2004 de oito espécies da família Lauraceae ocorrentes em um fragmento florestal localizado no centro-sul do estado do Paraná. As espécies foram analisadas pelos indicadores estruturais e dinâmicos: IVI, abundância, área basal, volume, distribuição diamétrica, distribuição espacial, recrutamento, mortalidade e incrementos. Os resultados demonstraram que, em 10 anos de dinâmica estrutural, a família Lauraceae, de maneira geral, manteve inalterada sua posição de importância na comunidade. Observou-se que as Lauráceas passam por aumento de densidade, porque o recrutamento está sendo maior que a mortalidade. Já o crescimento das Lauráceas tem sido muito baixo, tanto em diâmetro como em área basal e volume. Embora a maior parte das Lauráceas apresente um padrão dinâmico lento, algumas espécies passam por um intenso processo de mudanças, como é o caso da canela-amarela (Nectandra grandiflora Nees \& Mart. ex Nees), que aumentou a maioria dos seus indicadores estruturais e dinâmicos, constituindo-se na espécie de maior destaque entre as analisadas. Essa espécie apresenta recrutamento muito superior à mortalidade, distribuição diamétrica decrescente e ampla distribuição espacial. Esses elementos estão tornando essa espécie em uma das três mais importantes em toda a comunidade, juntamente com a araucária (Araucaria angustifolia (Bertol.) Kuntze) e a erva-mate (Ilex paraguariensis A.St.-Hil.). Concluiu-se que, em 10 anos, já é possível distinguir processos ecológicos importantes que podem servir como indicativos em Planos de Manejo para Florestas semelhantes de Araucária.
\end{abstract}

Palavras-chave: florestas de araucária; fitossociologia; dinâmica florestal; lauráceas.

\begin{abstract}
Several species of Lauraceae family are among the most common ones in the Araucaria Forest. They have good silvicultural and economic potential, but unfortunately they are still very poorly studied. This paper analyzes the structural changes of eight species of Lauraceae family during 1995-2004 in a forest located in the center-south region of Parana State, Brazil. The species were investigated through structural and dynamic indicators: importance value (IVI), abundance, basal area, trunk volume, diameter distribution, spatial pattern, recruitment, mortality and increments. The results showed that the structural position of the Lauraceae family was kept almost unaltered in the community during the ten-year period. It was also noticed that the Lauraceae family is increasing in terms of abundance due to the fact that recruitment has been greater than mortality. However, growth rates have been very low, either in diameter and basal area/volume. Although most Lauraceae species show a slow dynamic behavior, some of them have experienced an intense chance process, such as Canela-amarela (Nectandra grandiflora Nees \& Mart. ex Nees) which increased most of its structural and dynamic indicators, becoming the most remarkable species among all those studied. This species showed recruitment greater than mortality, a J-shaped diameter distribution and very wide spatial distribution. These elements have turned this species one of the three most important in the community together with Araucaria angustifolia (Bertol.) Kuntze and Ilex paraguariensis A.St.-Hil. It was concluded that, in ten years, it is already possible to distinguish important ecological processes that may be very useful in formulating Management Plans for similar Araucaria forests.
\end{abstract}

Keywords: araucaria florest; phytosociology; forest dynamics; laurel trees.

1. Acadêmica do Curso de Graduação em Engenharia Florestal, Setor de Ciências Agrárias, Universidade Federal do Paraná, CEP 80210-170, Curitiba (PR). Bolsista PET. geise@ufpr.br

2. Engenheira Florestal, Mestranda pelo Programa de Pós-Graduação em Engenharia Florestal, Setor de Ciências Agrárias, Universidade Federal do Paraná, CEP 80210-170, Curitiba (PR). Bolsista do CNPq. anacorte@ufpr.br

3. Engenheiro Florestal, Dr., Professor do Departamento de Ciências Florestais, Setor de Ciências Agrárias, Universidade Federal do Paraná, CEP 80210-170, Curitiba (PR). Bolsista do CNPq. sanquetta@ufpr.br

Recebido para publicação em 22/03/2005 e aceito em 16/10/2006. 


\section{INTRODUÇÃO}

A Floresta Ombrófila Mista, também chamada de Floresta de Araucária por possuir Araucaria angustifolia (Bertol.) Kuntze como sua espécie característica, ainda continua ameaçada pela ação humana. Seus remanescentes primários (floresta em estágio avançado de sucessão) somam cerca de $1,5 \%$ da área ocupada originalmente no estado do Paraná (Sanquetta, 2004). A proteção desses raros remanescentes é uma necessidade premente e um grande desafio para os órgãos ambientais, para a comunidade científica e para a sociedade como um todo.

A grande dificuldade de conservar as florestas de araucária remanescentes reside no fato de que a quase-totalidade da área está nas mãos de proprietários privados, que se sentem desestimulados pela obrigação legal de preservar suas florestas excedentes às APP's - Areas de Preservação Permanente sem poder manejá-las com a finalidade de geração de renda complementar. Esse cenário tem induzido à ilegalidade e à clandestinidade no corte da araucária e de outras espécies associadas.

Um desafio ainda maior consiste em responder aos detentores de mais de 2,7 milhões de hectares de florestas em estágios inicial e médio de sucessão (cerca de $23 \%$ da área original da Floresta de Araucária, conforme Sanquetta, 2004), qual o tratamento a dar para suas áreas, especialmente nas regiões de alta concentração de remanescentes nativos. Alguma opção à fiscalização e à proibição total precisa ser oferecida pelos gestores dos órgãos oficiais competentes e pelos especialistas. Infelizmente quase-nada tem sido feito nesse sentido.

Manejar racionalmente as florestas excedentes às APPs é uma opção viável (Sanquetta e Mattei, 2002), mas muito cuidado precisa ser tomado para não institucionalizar a dilapidação do pouco que resta da Floresta de Araucária. É preciso que a flexibilização ao uso racional dos recursos naturais oferecidos pela floresta seja acompanhada de conhecimento técnico sobre a biota e as populações florestais, noções do funcionamento do ecossistema como um todo e das práticas de manejo a aplicar para garantir a sustentabilidade da produção florestal e dos demais benefícios da floresta. Segundo Sanquetta et al. (2003), para manejar racionalmente essas florestas alteradas por seguidas ações antrópicas é preciso conhecer e respeitar sua capacidade regenerativa e produtividade. Tal capacidade está intimamente relacionada com três processos demográficos fundamentais, a saber: recrutamento, crescimento e mortalidade.

São escassos os estudos científicos sobre o manejo da Floresta de Araucária com enfoque sobre outras espécies que não o pinheiro (Araucaria angustifolia (Bertol.) Kuntze). Como se sabe, muitas espécies da família Lauraceae estão entre as mais comuns na estrutura da Floresta de Araucária, compondo o dossel e o subdossel desta. Muitas dessas espécies possuem bom potencial silvicultural, usos variados e valor econômico. Pesquisas sobre o comportamento dessas espécies são imprescindíveis para buscar formas alternativas de uso racional para a Floresta de Araucária, especialmente porque se pode assim descobrir as respostas a dar aos detentores dos remanescentes florestais em estágio inicial e médio de sucessão.

Este trabalho visa a apresentar resultados sobre as mudanças estruturais no período 1995-2004 concernentes a algumas espécies da família Lauraceae ocorrentes em um fragmento de Floresta de Araucária localizada no centro-sul do estado do Paraná. Os resultados desta pesquisa se fundamentam em análises partindo de um conjunto de parcelas permanentes remedidas anualmente por um período de 10 anos.

\section{MATERIAL E MÉTODOS}

\section{Área de Estudo}

A área de estudo está localizada no município de São João do Triunfo cujas coordenadas Utm são X:572.399 e Y: 7.160.235, situados no estado do Paraná, a uma distância de aproximadamente $125 \mathrm{~km}$ de Curitiba, na Estação Experimental pertencente à Universidade Federal do Paraná que possui área de cerca de 32 ha de superfície. Referências completas da localização são dadas por Pizatto (1999).

\section{Clima}

Segundo a classificação de Köppen, o clima da região é classificado como tipo $\mathrm{Cfb}$ - clima temperado sempre úmido com temperatura média inferior a $22^{\circ} \mathrm{C}$ durante o mês mais quente, sem estação seca, com verões frescos e mais de cinco geadas noturnas por ano. 


\section{Solo}

De acordo com Reinold de Hoog, citado por Pizatto (1999), o solo da floresta foi classificado como tipo Podzólico vermelho-amarelo distrófico com uma pequena porção do solo tipo Cambissolo distrófico álico.

\section{Vegetação}

A área de estudo trata-se de um fragmento de Floresta Ombrófila Mista ou Floresta com Araucária (IBGE, 1990) caracterizando-se pela associação da araucária com grupos diferenciados de espécies, em que o pinheiro ocupa o dossel superior da floresta juntamente com imbuias de grande porte. O segundo estrato é formado por um conjunto de espécies, e os estratos inferiores compreendem espécies como Cedrela fissilis, Ilex paraguariensis A.St.-Hil., diversas canelas (Nectranda spp., Ocotea spp.), mirtáceas (Myrcia spp., Eugenia spp., Campomanesia sp.) entre outras.

Segundo Longhi (1980), essa floresta sofreu algumas intervenções no passado, porém ainda mantém em sua estrutura sinais de sua composição original.

\section{Metodologia}

Os dados analisados neste trabalho foram coletados a partir de julho de 1995 e fazem parte do PELD - Programa de Pesquisas Ecológicas de Longa Duração, Site 9, financiado pelo CNPq - Conselho Nacional de Desenvolvimento Científico e Tecnológico e instituído em todos os principais Biomas brasileiros (Seeliger et al., 2002).

Foram instaladas quatro parcelas das quais três possuem 1 ha de forma quadrada $(100 \times 100 \mathrm{~m}) \mathrm{e}$ uma parcela com 0,5 ha, conforme citado por Pizatto (1999). Todas as parcelas estão divididas em subparcelas de $10 \times 10 \mathrm{~m}$, compreendendo um total de 350 unidades amostrais de $100 \mathrm{~m}^{2}$. Essas parcelas vêm sendo remedidas anualmente, realizando-se também o registro das árvores recrutas (ingressas) e mortas.

Todas as árvores com DAP (diâmetro à altura do peito - 1,30 m) maior ou igual a $10 \mathrm{~cm}$ são identificadas, pintadas na altura de medição e numeradas com etiquetas. Exsicatas de todas as espécies são preparadas e armazenadas nos herbários do Laboratório de Inventário Florestal e do Departamento de Ciências Florestais, do Curso de Engenharia Florestal da UFPR. As árvores têm sido remedidas anualmente, sempre no inverno, utilizando-se fita métrica com precisão de milímetros. Árvores mortas (mortalidade), bem como os indivíduos que passaram a atingir o tamanho mínimo de medição a cada ocasião (recrutamento) foram registrados e computados apropriadamente.

Os dados foram anotados em formulários de papel e, posteriormente, digitados em computador. As taxas de crescimento diamétrico (IPA - incremento periódico anual), mortalidade e recrutamento foram calculados para o período de 1995-2004. O crescimento anual em DAP foi calculado partindo da simples diferença entre as medidas nas duas ocasiões. A partir do crescimento em DAP, foram efetuados cálculos de crescimento em área basal e volume. Para a obtenção do volume utilizou-se uma equação hipsométrica expressão (1) (Pizatto, 1999) e um polinômio de $5^{-}$grau expressão (2), descritos a seguir, tendo por base árvores cubadas em pé com pentaprisma de Wheeler e medidas com hipsômetro de Blume-Leiss, considerando apenas a família Lauraceae. As medidas de altura foram tomadas na extremidade superior da copa das árvores, ou seja, as medidas se referem à altura total e não no ponto de inversão morfológica ou na posição da altura comercial.

As alturas estimadas foram calculadas segundo a equação hipsométrica ajustada por Pizatto (1999), que apresenta os seguintes parâmetros:

$h t_{\text {est }}=$ dap $^{2} /\left(-79,85297+20,005797 d a p+0,113487\right.$ dap $\left.^{2}\right)$

$\left[\mathrm{R}^{2}=0,6401 ; \operatorname{Syx} \%=16,21 ; \mathrm{F}=1260,84\right]$

Em que: hest $=$ altura estimada $(\mathrm{m})$.

O polinômio de $5^{\underline{0}}$ grau utilizado para os cálculos dos volumes está apresentado abaixo na expressão 
$d i / d a p=1,2000-1,5093+3,1739\left(\frac{h i}{h t}\right)^{2}+0,5433\left(\frac{h i}{h t}\right)^{3}-8,9023\left(\frac{h i}{h t}\right)^{4}+4,8832\left(\frac{h i}{h t}\right)^{5}$

Em que: $d_{i}=$ diâmetro da árvore a uma dada altura ou comprimento de tora em centímetros; hi $=$ altura parcial do fuste ou comprimento de tora em metros; ht $=$ altura total da árvore.

Neste trabalho, foram analisadas apenas as espécies que fazem parte da família Lauraceae, as quais foram levantadas nas 350 unidades amostrais. (Tabela 1).

TABELA 1: Lista das espécies da família Lauraceae encontradas em uma Floresta com Araucária do Sul do Brasil.

TABLE 1: Species of Lauraceae family found in a Forest with Araucária in the south of Brazil.

\begin{tabular}{ll}
\hline Nome vulgar & \multicolumn{1}{c}{ Nome científico } \\
\hline Canela-amarela & Nectandra grandiflora Nees \& Mart. ex Nees. \\
Canela-coqueiro & Ocotea sp. \\
Canela-guaicá & Ocotea puberula (Rich) Nees \\
Canela-imbuia & Nectandra sp. \\
Canela-sebo & Cinnamomum sellowianum (Nees \& Mart.) Kosterm. \\
Imbuia & Ocotea porosa (Mez) L. Barroso \\
Pau-alho & Cinnamomum vesiculosum (Nees) Kosterm. \\
Pau-andrade & Persea pyrifolia Nees \& Mart. \\
\hline
\end{tabular}

Além das análises da dinâmica estrutural, foi também avaliado o padrão de distribuição espacial das espécies listadas por meio de mapas de localização e do cálculo do padrão de dispersão pelo Índice de Morisita (M), conforme citado por Scolforo (1998).

De acordo com Barros (1986), o Índice de Morisita é pouco influenciado pelo tamanho da unidade amostral e apresenta excelente qualidade na detecção do grau de dispersão. Sua formulação é dada pela equação (3).

$M=\left[\left(\sum x^{2}\right) /(N(N-1)] n\right.$

Em que: $M=$ Índice de Morisita; $n=$ número total de parcelas amostradas; $N=$ número total de indivíduos por espécie, contidos nas $n$ parcelas; $x$ = número de indivíduos na parcela.

Conforme citado por Scolforo (1998), a interpretação desse índice deve seguir o seguinte critério:

- $\quad M>1 \Rightarrow$ Distribuição agregada;

- $M=1 \Rightarrow$ Distribuição aleatória;

- $M=0 \Rightarrow$ Distribuição uniforme.

Outra análise também realizada neste estudo diz respeito à conformação das distribuições diamétricas das espécies em tela.

\section{RESULTADOS E DISCUSSÕES}

\section{Indicadores estruturais}

A Tabela 2 mostra os principais indicadores estruturais da comunidade de Lauraceae na floresta em estudo. Em primeiro lugar evidencia-se que a participação dessa família é de aproximadamente $50 \%$ nos $300 \%$ computados pelo Î́ndice de Valor de Importância, ou seja, a família representa aproximadamente $25 \%$ do IVI da comunidade florestal composta de árvores com DAP acima de $10 \mathrm{~cm}$. Observa-se ainda, com base nos valores de IVI ao longo dos 10 interstícios temporais, que não houve mudança significativa na participação das Lauráceas na comunidade, embora algumas espécies tenham ganhado em importância e outras perdido. O maior IVI das Lauráceas foi de Nectandra grandiflora (canela-amarela), que se elevou muito nos 10 anos de avaliação. Por outro lado, a Ocotea sp. (canela-coqueiro) e a Nectandra sp. (canelaimbuia) perderam bastante terreno na comunidade, conforme expresso em termos de IVI. 
TABELA 2: Indicadores estruturais das populações da família Lauraceae em uma Floresta com Araucária do Sul do Brasil.

TABLE 2: Structural pointers of populations of Lauraceae family in a Forest with Araucária in the south of Brazil.

\begin{tabular}{|c|c|c|c|c|c|c|c|c|c|c|c|}
\hline \multirow{2}{*}{ Variável } & \multirow{2}{*}{ Espécie } & \multicolumn{10}{|c|}{ Ano de Medição } \\
\hline & & 1995 & \begin{tabular}{|c|}
1996 \\
\end{tabular} & 1997 & \begin{tabular}{|l|l|}
1998 \\
\end{tabular} & 1999 & 2000 & 2001 & 2002 & 2003 & 2004 \\
\hline \multirow{9}{*}{ IVI (\%) } & Canela-amarela & 14,51 & 15,28 & 16,94 & 18,47 & 18,68 & 18,68 & 17,52 & 17,78 & 18,01 & 18,68 \\
\hline & Canela-coqueiro & 3,62 & 3,86 & 3,63 & 1,54 & 1,58 & 1,58 & 3,56 & 3,04 & 2,92 & 1,58 \\
\hline & Canela-guaicá & 9,16 & 7,53 & 7,19 & 6,83 & 6,79 & 6,79 & 7,32 & 7,23 & 7,08 & 6,79 \\
\hline & Canela-imbuia & 5,64 & 5,73 & 5,66 & 3,18 & 3,16 & 3,16 & 4,96 & 4,93 & 4,81 & 3,16 \\
\hline & Canela-sebo & 3,31 & 3,39 & 3,34 & 3,03 & 3,01 & 3,01 & 3,12 & 2,89 & 2,93 & $\overline{3,01}$ \\
\hline & Imbuia & 8,93 & 9,36 & 8,94 & 9,34 & 9,31 & 9,31 & 8,62 & 8,53 & 8,26 & $\overline{9,31}$ \\
\hline & Pau-alho & 4,06 & 4,08 & 4,21 & 6,11 & 6,11 & 6,11 & 4,93 & 5,09 & 5,52 & 6,11 \\
\hline & Pau-andrade & 1,62 & 1,79 & 1,69 & 1,57 & 1,56 & 1,56 & 1,61 & 1,61 & 1,52 & 1,56 \\
\hline & Total & 50,85 & 51,01 & 51,61 & 50,06 & 50,22 & 50,22 & 51,64 & 51,11 & 51,05 & 50,22 \\
\hline \multirow{9}{*}{ Abundância (no./ha) } & Canela-amarela & 63,71 & 65,14 & 68,00 & \begin{tabular}{|l|}
68,57 \\
\end{tabular} & 71,71 & 73,43 & 74,86 & 77,14 & \begin{tabular}{|l|}
80,29 \\
\end{tabular} & 83,43 \\
\hline & Canela-coqueiro & 2,00 & 2,29 & 2,29 & 2,29 & 2,29 & 2,29 & 2,29 & 2,29 & 2,29 & 2,29 \\
\hline & Canela-guaicá & 18,00 & 16,29 & 16,29 & 17,14 & 17,14 & 17,71 & 17,71 & 17,43 & 17,43 & 17,43 \\
\hline & Canela-imbuia & 11,14 & 11,14 & 11,43 & 11,14 & 10,57 & 10,57 & 10,29 & 10,29 & 10,29 & 10,29 \\
\hline & Canela-sebo & 6,29 & 6,29 & 6,57 & 6,86 & 6,86 & 6,57 & 6,57 & 6,29 & 7,14 & 7,14 \\
\hline & Imbuia & 10,57 & 10,29 & 10,00 & 10,29 & 10,29 & 10,00 & 10,00 & 10,00 & 10,00 & 10,00 \\
\hline & Pau-alho & 10,86 & 10,86 & 12,29 & 13,14 & 15,71 & \begin{tabular}{|c|}
17,43 \\
\end{tabular} & 18,00 & \begin{tabular}{|c|}
19,43 \\
\end{tabular} & 23,14 & 23,43 \\
\hline & Pau-andrade & 0,86 & 1,43 & 1,43 & 1,71 & 1,71 & 1,71 & 1,71 & 1,71 & 1,71 & 1,71 \\
\hline & Total & 123,43 & 123,71 & 128,29 & 131,14 & 136,291 & 139,71 & 141,43 & 144,57 & 152,29 & 155,71 \\
\hline \multirow{9}{*}{ Área basal $\left(\mathrm{m}^{2} / \mathrm{ha}\right)$} & Canela-amarela & 1,42 & 1,47 & 1,51 & 1,56 & 1,63 & 1,71 & 1,71 & 1,76 & 1,84 & 1,96 \\
\hline & Canela-coqueiro & 0,69 & 0,70 & 0,71 & 0,71 & 0,71 & 0,71 & 0,71 & 0,73 & 0,55 & 0,55 \\
\hline & Canela-guaicá & 1,88 & 1,27 & 1,21 & 1,26 & 1,28 & 1,32 & 1,32 & 1,35 & 1,37 & 1,42 \\
\hline & Canela-imbuia & 0,92 & 0,88 & 0,89 & 0,89 & 0,87 & 0,88 & 0,88 & 0,82 & 0,84 & 0,86 \\
\hline & \begin{tabular}{|l|} 
Canela-sebo \\
\end{tabular} & 0,33 & 0,31 & 0,32 & 0,33 & 0,34 & 0,32 & 0,32 & 0,32 & 0,26 & 0,28 \\
\hline & Imbuia & 2,22 & 2,26 & 2,18 & 2,20 & 2,21 & 2,22 & 2,22 & 2,26 & 2,28 & 2,31 \\
\hline & Pau-alho & 0,40 & 0,35 & 0,37 & 0,39 & 0,42 & 0,45 & 0,45 & 0,47 & 0,50 & 0,54 \\
\hline & Pau-andrade & 0,01 & 0,01 & 0,01 & 0,02 & 0,02 & 0,02 & 0,02 & 0,02 & 0,02 & 0,02 \\
\hline & Total & 7,86 & 7,26 & 7,21 & 7,35 & 7,47 & 7,65 & 7,65 & 7,74 & 7,66 & 7,95 \\
\hline \multirow{9}{*}{$\begin{array}{l}\text { Volume total do fuste } \\
\left(\mathrm{m}^{3} / \mathrm{ha}\right)\end{array}$} & Canela-amarela & 18,05 & 18,70 & 19,15 & 19,84 & 20,68 & 21,75 & 22,41 & 23,52 & 25,14 & 24,70 \\
\hline & Canela-coqueiro & 16,73 & 17,06 & 17,07 & 17,15 & 17,10 & 17,30 & 17,81 & 12,04 & 12,23 & 11,86 \\
\hline & Canela-guaicá & 30,99 & 20,06 & 19,06 & 19,70 & 20,10 & 20,71 & 21,11 & 21,53 & 22,21 & 22,75 \\
\hline & Canela-imbuia & 14,18 & 13,45 & 13,63 & 13,70 & 13,38 & 13,60 & 12,52 & 12,76 & 13,22 & 13,38 \\
\hline & Canela-sebo & 4,82 & 4,53 & 4,64 & 4,76 & 4,87 & 4,61 & 4,68 & 3,66 & 3,87 & 3,96 \\
\hline & Imbuia & 46,96 & 48,15 & 46,96 & 47,08 & 47,27 & 47,64 & 48,73 & 48,89 & 49,51 & 49,32 \\
\hline & Pau-alho & 5,59 & 4,85 & 5,08 & 5,27 & 5,63 & 5,99 & 6,19 & 6,62 & 7,01 & 7,25 \\
\hline & Pau-andrade & 0,09 & 0,13 & 0,13 & 0,22 & 0,22 & 0,23 & 0,24 & 0,25 & 0,26 & 0,27 \\
\hline & Total & 137,41 & 126,94 & 125,73 & 127,71 & 129,24 & 131,82 & 133,69 & 129,26 & 133,46 & 133,49 \\
\hline \multirow{9}{*}{ DAP médio $(\mathrm{cm})$} & Canela-amarela & 21,12 & 21,43 & 21,88 & $|22,47|$ & 23,27 & 24,12 & 24,64 & 25,63 & 26,60 & 27,39 \\
\hline & Canela-coqueiro & 38,21 & 40,85 & 40,88 & 41,00 & 40,90 & 41,36 & 41,63 & 38,59 & $38,97 \mid$ & 37,68 \\
\hline & Canela-guaicá & 25,60 & 19,97 & 19,43 & 20,42 & 20,75 & 21,50 & 21,75 & 21,84 & 22,37 & 22,66 \\
\hline & Canela-imbuia & 26,65 & 25,98 & 26,39 & 26,12 & 25,18 & 25,46 & 24,30 & 24,61 & 25,01 & 25,25 \\
\hline & Canela-sebo & 16,89 & 16,80 & 17,53 & 18,24 & 18,54 & 17,66 & 17,91 & 16,25 & 17,76 & 18,04 \\
\hline & Imbuia & 35,91 & 35,88 & 34,46 & 35,01 & 35,19 & 35,11 & 35,44 & 35,80 & 36,02 & 36,08 \\
\hline & Pau-alho & 7,46 & 7,16 & 7,84 & 8,29 & 9,45 & 10,39 & 10,78 & 11,63 & 13,25 & 13,58 \\
\hline & Pau-andrade & 5,76 & 9,19 & 9,26 & 12,30 & 12,32 & 12,64 & 12,85 & 13,05 & 13,32 & 13,44 \\
\hline & Total & 20,95 & $\mid 20,91$ & 22,21 & 22,98 & 23,20 & 23,53 & 23,66 & 23,42 & 24,16 & 24,26 \\
\hline
\end{tabular}

A abundância (densidade) da família Lauraceae cresceu no período, com destaque para a Nectandra grandiflora (canela-amarela) e o Cinnamomum vesiculogum (pau-alho), que aumentaram em número de árvores de forma expressiva. No tocante à área basal, evidencia-se que a participação das Lauráceas não 
aumentou de forma expressiva, continuando com valores na faixa de $7,9 \mathrm{~m}^{2} / \mathrm{ha}$, que representa mais ou menos $25 \%$ da área basal total (Pizatto, 1999). Todas as espécies possuem áreas basais baixas, reflexo do tamanho dos indivíduos e/ou da reduzida abundância. No caso da Ocotea porosa (imbuia) ocorrem árvores de grande porte na floresta (algumas com cerca de $1 \mathrm{~m}$ de DAP), mas são poucos os representantes dessa espécie na comunidade. Já a Nectandra grandiflora (canela-amarela), em que pese sua considerável abundância, não possui uma grande área basal, haja vista sua população de constituir predominantemente de indivíduos com DAP pequeno.

A família das Lauráceas apresentou para a variável volume, um razoável decréscimo, de cerca de 137 para 133 metros cúbicos/ha. Percebe-se ainda que a imbuia vem crescendo a taxas razoáveis, passando de 47 a 49 metros cúbicos/ha. Destaque merece a canela-amarela que, em 1994, possuía $18 \mathrm{~m}^{3} / \mathrm{ha}$ e, em 2004 , atingiu quase $25 \mathrm{~m}^{3} / \mathrm{ha}$.

O DAP médio da comunidade de Lauráceas, em 10 anos, passou de 21 para quase $25 \mathrm{~cm}$, um aumento considerável. Os maiores aumentos em DAP ocorreram para a Nectandra grandiflora (canelaamarela), Cinnamomum vesiculogum (pau-alho) e Persea pagrifoia (pau-andrade). No último caso, o DAP médio saltou de 5,76 cm em 1995 para mais de 13,44 cm em 2004, ou seja, cerca de 133\% em crescimento. Uma redução em DAP considerável foi registrada para a Ocotea puberula (canela-guaicá).

Analisando-se as distribuições diamétricas (Figura 1), percebe-se adicionalmente que apenas a Nectandra grandiflora (canela-amarela) apresenta uma distribuição tipicamente decrescente na forma de "J invertido". Essa forma é considerada aquela que mantém a regeneração da espécie dentro de um fluxo contínuo. Algumas canelas - mais nitidamente Ocotea puberula (canela-guaicá) e Nectandra sp. (canelaimbuia) e a Ocotea porosa (imbuia) apresentaram distribuições diamétricas com poucos elementos nas classes menores, indicando descontinuidade de regeneração.

Outro fato que se extrai da Figura 1 é o grande aumento no número de árvores nas classes inferiores da distribuição diamétrica da Nectandra grandivlora (canela-amarela) e Persea pyrifolia (pau-andrade) de 1995 para 2004, reflexo do elevado recrutamento no período.

A Figura 2 mostra o padrão de distribuição espacial das espécies de Lauraceae nas parcelas de estudo, explicando a existência de agregação e o seu comportamento associativo. Evidencia-se, primeiramente, que a Nectandra grandiflora (canela-amarela), a espécie de maior densidade, está representada nas quatro parcelas, porém ocorrendo com maior freqüência na parcela 1. Essa parcela está numa fase sucessional intermediária e caracteriza-se pelo predomínio da araucária (Araucaria angustifolia (Bertol.) Kuntze) no dossel (Pizatto, 1999).

As espécies que ocorreram em todas as parcelas foram: Nectandra grandiflora (canela-amarela), Ocotea puberula (canela-guaicá), Ocotea poropsa (imbuia) e Cinnamomum vesiculogum (pau-alho), enquanto Ocotea sp. (canela-coqueiro), Nectandra sp. (canela-imbuia) e Persea pyrifolia (pau-andrade) ocorreram em apenas uma. Ademais, pode-se perceber que a parcela que possui o maior número de espécies é a 3, que contém todas as espécies de Lauráceas, exceto Persea pyrifolia (pau-andrade). Essa parcela é a mais avançada no curso da sucessão (Bittencourt et al., 2004).

Outra observação importante diz respeito ao padrão de agrupamento das espécies. Foi realizado também o cálculo que demonstra se a espécies apresentam padrões de distribuição agregada ou não, segundo o Índice de Morisita. Os valores encontrados para as espécies estão apresentados na Tabela 3, mostrando que todas as espécies apresentaram padrão de distribuição agregada. No caso do pau-alho e da canela-amarela os resultados foram bem próximos a 1, indicando, portanto, uma distribuição mais próxima da aleatória do que da agregada. Os resultados desse índice demonstram padrões de agregação para as espécies analisadas, o que deve ter sido determinado tanto por condições microclimáticas encontradas em cada parcela analisada, quanto pela fonte de sementes em cada local e seu potencial de dispersão por diferentes vetores. 

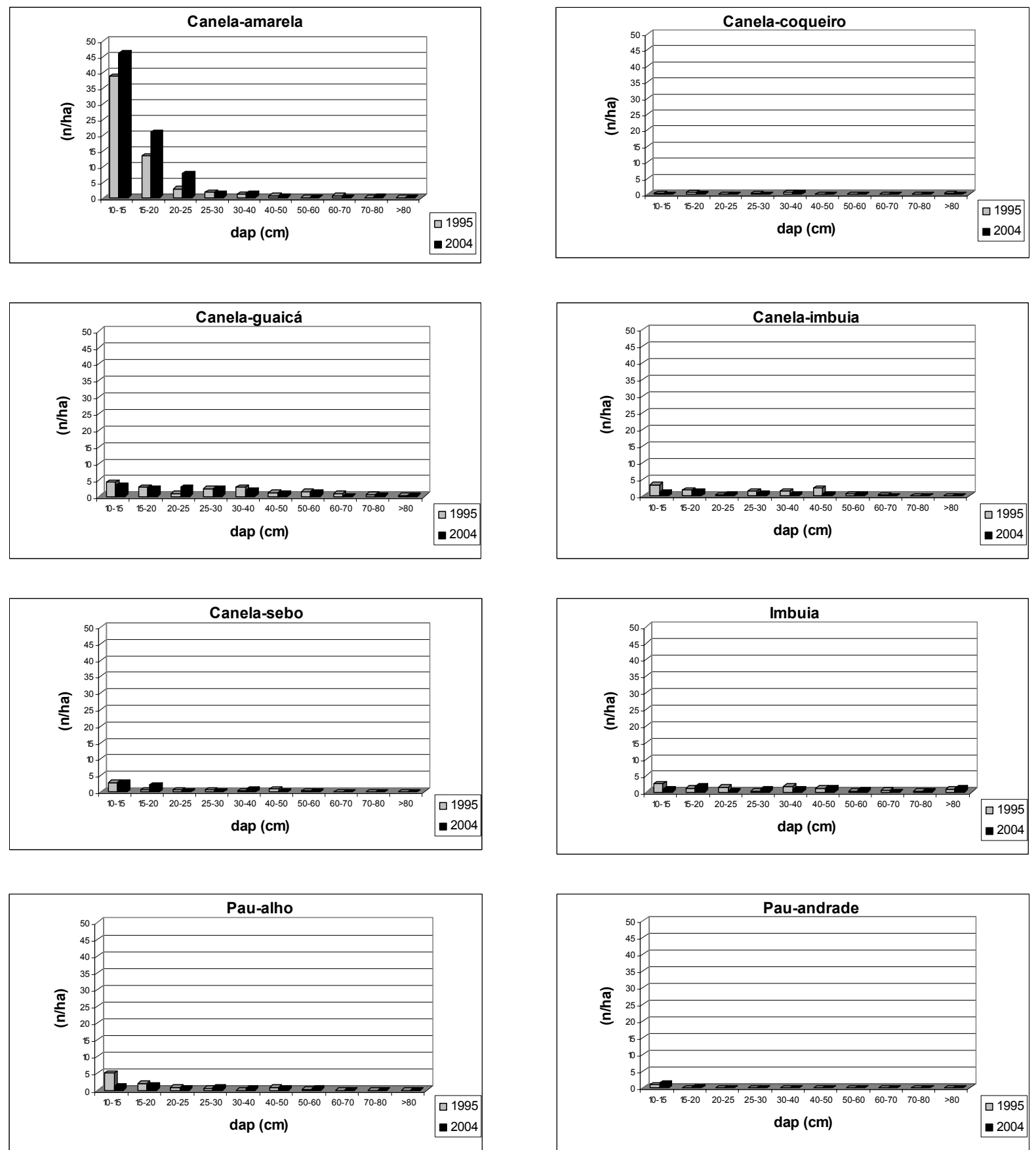

FIGURA 1: Distribuições diamétricas para as espécies da família Lauraceae em uma Floresta com Araucária do Sul do Brasil.

FIGURE 2: Diameter distributions for the species of Lauraceae family in a Forest with Araucaria in the South of Brazil. 


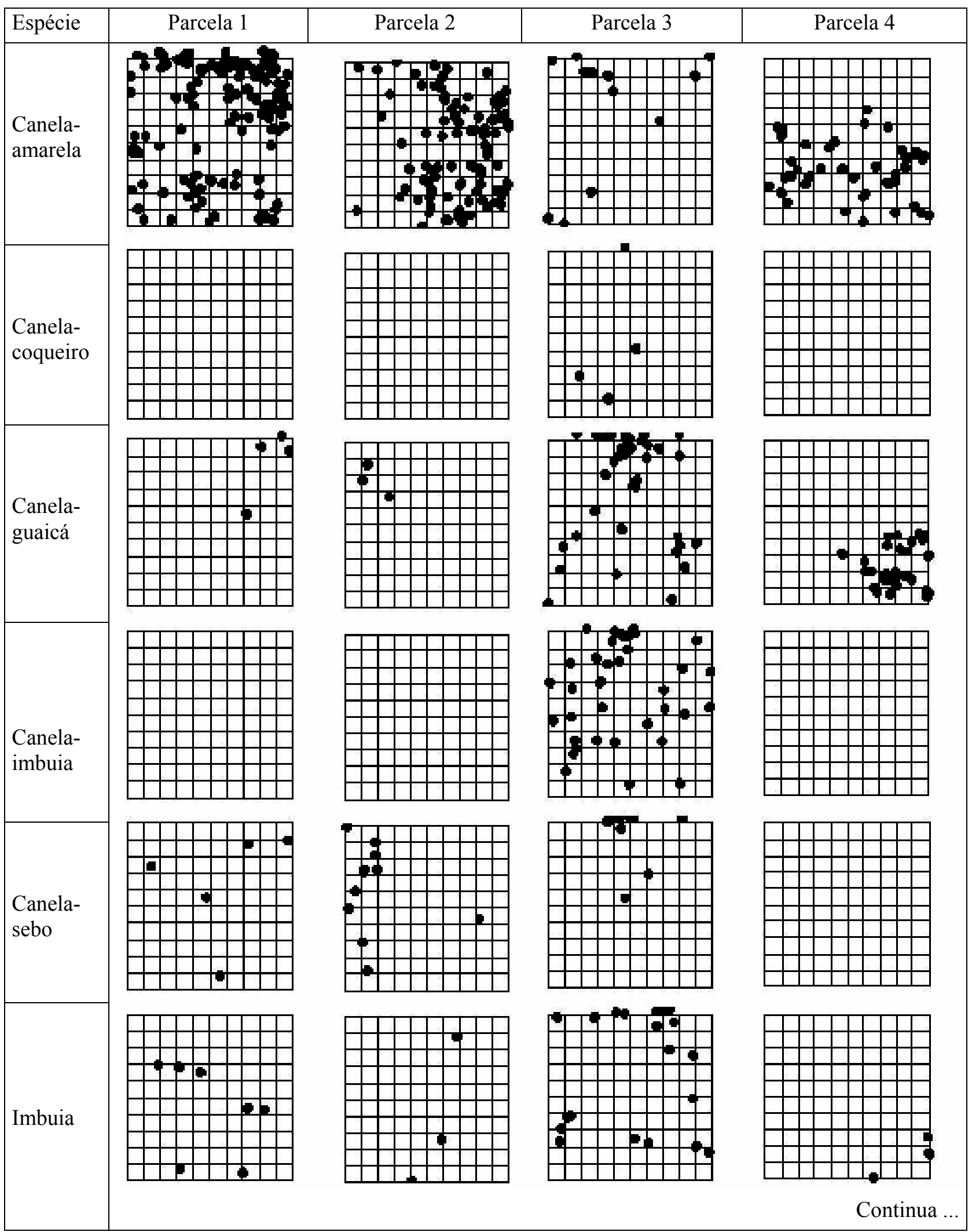




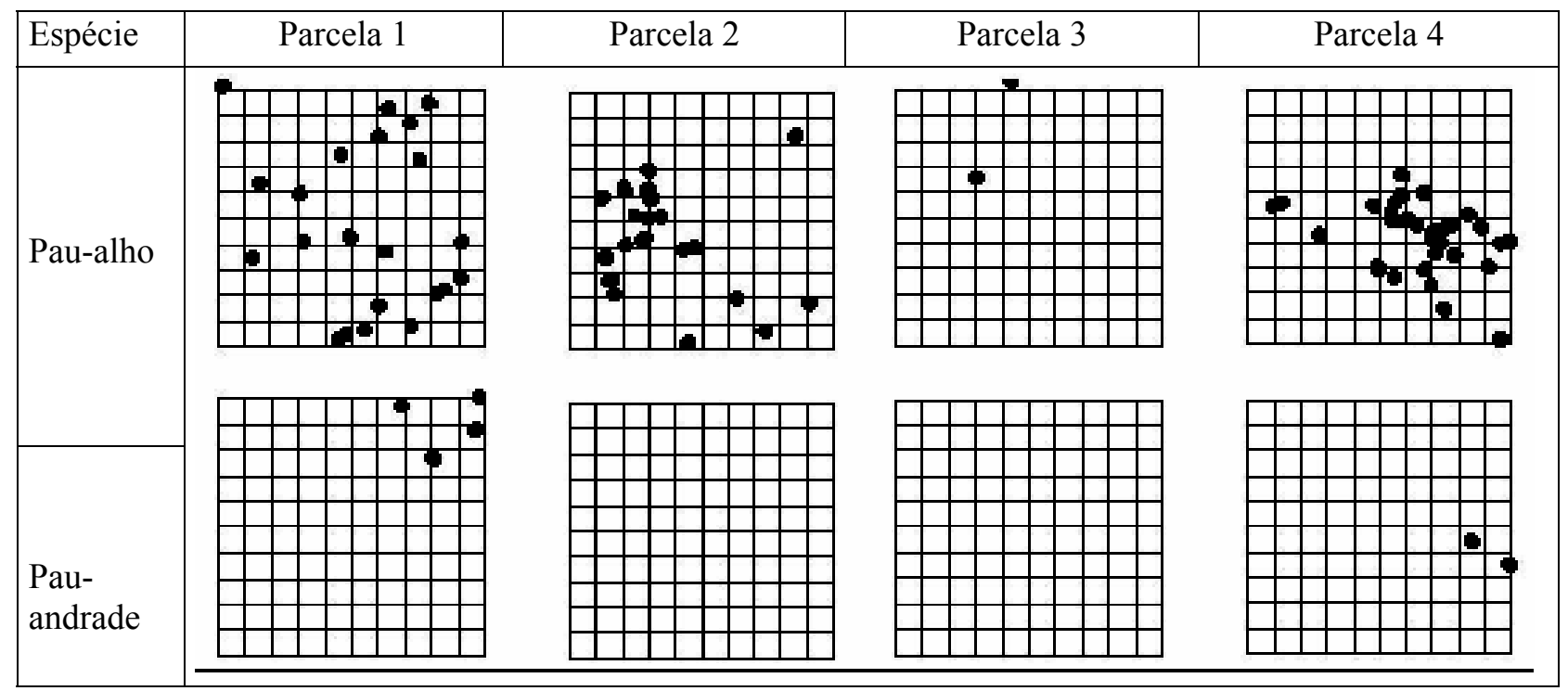

FIGURA 2: Distribuição espacial das espécies de Lauraceae nas parcelas de estudo em uma Floresta com Araucária do Sul do Brasil.

FIGURE 2: Space distributions for the species of Lauraceae family in a Forest with Araucaria in the South of Brazil.

TABELA 3: Índice de distribuição espacial de Morisita em uma Floresta com Araucária do Sul do Brasil.

TABLE 3: Index of Morisita space distribution in a Forest with Araucaria in the south of Brazil.

\begin{tabular}{ll|c}
\hline Nome vulgar & \multicolumn{1}{|c}{ Nome científico } & Índice de Morisita (M) \\
\hline Canela-amarela & Nectandra grandiflora & 1,2 \\
Canela-coqueiro & Ocotea sp. & 3,9 \\
Canela-guaicá & Ocotea puberula & 1,5 \\
Canela-imbuia & Nectandra sp. & 3,6 \\
Canela-sebo & Cinnamomum sellowianum & 1,4 \\
Imbuia & Ocotea porosa & 1,5 \\
Pau-alho & Cinnamomum vesiculosum & 1,1 \\
Pau-andrade & Persea pyrifolia & 2,1 \\
\hline
\end{tabular}

\section{Indicadores dinâmicos}

A Tabela 4 apresenta os indicadores dinâmicos de recrutamento, mortalidade e incremento (em DAP, área basal e volume) para as unidades amostrais em análise. Os resultados contidos na tabela mostram que as Lauráceas apresentaram um saldo positivo em abundância ao final do período em função de ter havido um recrutamento bem maior do que a mortalidade. O número médio de árvores mortas foi de 14 indivíduos por hectare contra 46 recrutas na mesma unidade. A canela-amarela foi a espécie que se destacou em termos de recrutamento, acompanhada de perto do pau-alho. Ao contrário, a imbuia e canela-coqueiro tiveram recrutamento muito modesto. Já em termos de mortalidade, verificou-se que as espécies com maiores índices foram a canela-guaicá, canela amarela e o pau-alho, as últimas duas com elevado recrutamento também, como mencionado anteriormente.

Os incrementos das Lauráceas, em geral, foram muito baixos ou negativos, demonstrando que as árvores dessas espécies estão em uma fase quase de estagnação. Tanto em DAP médio, quanto em área basal e volume os incrementos foram negativos.

Com base nas Tabelas 2 e 4 pode-se, então, afirmar que as Lauráceas estão se mantendo em condição de relativa estabilidade na floresta, fato refletido pelos valores de IVI. Adicionalmente, essa família vem apresentando aumento em sua abundância por causa do recrutamento, mas perdendo alguma representatividade nas classes dimensionais mais elevadas (árvores maiores), diante dos baixos incrementos em DAP, área basal e volume, e à mortalidade. 
TABELA 4: Indicadores dinâmicos da família Lauraceae na floresta em uma Floresta com Araucária do Sul do Brasil.

TABLE 4: Dynamic pointers of Lauraceae family in the forest in a Forest with Araucaria in the south of Brazil.

\begin{tabular}{|c|c|c|c|c|c|c|c|c|c|c|c|}
\hline \multirow{2}{*}{ Variável } & \multirow{2}{*}{ Espécie } & \multicolumn{10}{|c|}{ Anos de Medição } \\
\hline & & 1995 & 1996 & 1997 & 1998 & 1999 & 2000 & 2001 & 2002 & 2003 & 2004 \\
\hline \multirow{9}{*}{$\begin{array}{l}\text { Recrutamento cumulativo } \\
\text { (n./ha/ano) }\end{array}$} & Canela-amarela & 0,00 & 1,71 & 4,57 & 5,43 & 8,57 & 10,57 & 13,14 & 15,43 & 18,86 & 22,57 \\
\hline & Canela-coqueiro & 0,00 & 0,29 & 0,29 & 0,29 & 0,57 & 0,57 & 0,57 & 0,57 & 0,57 & 0,57 \\
\hline & Canela-guaicá & 0,00 & 1,43 & 2,00 & 2,86 & 2,86 & 3,43 & 3,43 & 3,71 & 3,71 & 3,71 \\
\hline & Canela-imbuia & 0,00 & 0,57 & 0,86 & 0,86 & 0,86 & 0,86 & 0,86 & 0,86 & 0,86 & 0,86 \\
\hline & Canela-sebo & 0,00 & 0,29 & 0,57 & 0,86 & 0,86 & 0,86 & 0,86 & 0,86 & 1,71 & 1,71 \\
\hline & Imbuia & 0,00 & 0,00 & 0,00 & 0,29 & 0,29 & 0,29 & 0,29 & 0,29 & 0,29 & 0,29 \\
\hline & Pau-alho & 0,00 & 0,57 & 2,00 & 2,86 & 5,43 & 7,43 & 8,57 & 10,00 & 14,57 & 14,57 \\
\hline & Pau-andrade & 0,00 & 0,57 & 0,57 & 0,86 & 0,86 & 0,86 & 0,86 & 0,86 & 0,86 & 2,00 \\
\hline & Total & 0,00 & 5,43 & 10,86 & 14,29 & 20,29 & 24,86 & 28,57 & 32,57 & 41,43 & 46,29 \\
\hline \multirow{9}{*}{$\begin{array}{l}\text { Mortalidade cumulativa } \\
\text { (n./ha/ano) }\end{array}$} & Canela-amarela & 0,00 & 0,29 & 0,29 & 0,57 & 0,57 & 1,14 & 2,29 & 2,29 & 2,57 & 3,14 \\
\hline & Canela-coqueiro & 0,00 & 0,00 & 0,00 & 0,00 & 0,00 & 0,00 & 0,00 & 0,00 & 0,00 & 0,00 \\
\hline & Canela-guaicá & 0,00 & 3,14 & 3,71 & 3,71 & 3,71 & 3,71 & 3,71 & 4,29 & 4,29 & 4,29 \\
\hline & Canela-imbuia & 0,00 & 0,57 & 0,86 & 1,14 & 1,71 & 1,71 & 2,00 & 2,00 & 2,00 & 2,00 \\
\hline & Canela-sebo & 0,00 & 0,29 & 0,29 & 0,29 & 0,29 & 0,57 & 0,57 & 0,86 & 0,86 & 0,86 \\
\hline & Imbuia & 0,00 & 0,29 & 0,29 & 0,29 & 0,29 & 0,57 & 0,57 & 0,57 & 0,86 & 0,86 \\
\hline & Pau-alho & 0,00 & 0,57 & 0,57 & 0,57 & 0,57 & 0,86 & 1,43 & 1,43 & 2,29 & 3,14 \\
\hline & Pau-andrade & 0,00 & 0,00 & 0,00 & 0,00 & 0,00 & 0,00 & 0,00 & 0,00 & 0,00 & 0,00 \\
\hline & Total & 0,00 & 5,14 & 6,00 & 6,57 & 7,14 & 8,57 & 10,57 & 11,43 & 12,86 & 14,29 \\
\hline \multirow{9}{*}{$\begin{array}{l}\text { ICA médio DAP } \\
(\mathrm{cm})\end{array}$} & Canela-amarela & 0,00 & $-0,31$ & $-10,45$ & $-0,59$ & $-0,80$ & $-0,85$ & $-0,52$ & $-0,99$ & $-0,97$ & $-0,78$ \\
\hline & Canela-coqueiro & 0,00 & $-2,64$ & $-0,03$ & $-0,12$ & 0,10 & $-0,46$ & $-0,27$ & 3,04 & $-0,38$ & 1,29 \\
\hline & Canela-guaicá & 0,00 & 5,63 & 0,54 & $-0,99$ & $-0,33$ & $-0,75$ & $-0,25$ & $-0,10$ & $-0,53$ & $-0,29$ \\
\hline & Canela-imbuia & 0,00 & 0,67 & $-0,41$ & 0,27 & 0,94 & $-0,28$ & 1,16 & $-0,31$ & $-0,40$ & $-0,24$ \\
\hline & Canela-sebo & 0,00 & 0,09 & $-0,73$ & $-0,71$ & $-0,29$ & 0,87 & $-0,25$ & 1,67 & $-1,51$ & $-0,29$ \\
\hline & Imbuia & 0,00 & 0,04 & 1,42 & $-0,55$ & $-0,18$ & 0,08 & $-0,33$ & $-0,35$ & $-0,22$ & $-0,06$ \\
\hline & Pau-alho & 0,00 & 0,30 & $-0,68$ & $-0,45$ & $-1,15$ & $-0,95$ & $-0,39$ & $-0,84$ & $-1,62$ & $-0,34$ \\
\hline & Pau-andrade & 0,00 & $-3,44$ & $-0,07$ & $-3,03$ & $-0,03$ & $-0,31$ & $-0,22$ & $-0,20$ & $-0,27$ & $-0,12$ \\
\hline & Médio & 0,00 & 0,34 & $-10,41$ & $-6,18$ & $-1,74$ & $-2,64$ & $-1,07$ & 1,93 & $-5,90$ & $-0,83$ \\
\hline \multirow{9}{*}{$\begin{array}{l}\text { ICA Área basal } \\
\left(\mathrm{m}^{2} / \mathrm{ha} / \mathrm{ano}\right)\end{array}$} & Canela-amarela & 0,00 & $-0,05$ & $-0,04$ & $-0,05$ & $-0,07$ & $-0,08$ & 0,00 & $-0,05$ & $-0,09$ & $-0,12$ \\
\hline & Canela-coqueiro & 0,00 & $-0,02$ & 0,00 & 0,00 & 0,00 & $-0,01$ & 0,00 & $-0,02$ & 0,18 & $-0,01$ \\
\hline & Canela-guaicá & 0,00 & 0,61 & 0,06 & $-0,05$ & $-0,03$ & $-0,04$ & 0,00 & $-0,02$ & $-0,02$ & $-0,04$ \\
\hline & Canela-imbuia & 0,00 & 0,04 & $-0,01$ & 0,00 & 0,02 & $-0,01$ & 0,00 & 0,06 & $-0,01$ & $-0,03$ \\
\hline & Canela-sebo & 0,00 & 0,02 & $-0,01$ & $-0,01$ & $-0,01$ & 0,02 & 0,00 & $-0,01$ & 0,06 & $-0,02$ \\
\hline & Imbuia & 0,00 & $-0,04$ & 0,07 & $-0,01$ & $-0,01$ & $-0,02$ & 0,00 & $-0,04$ & $-0,01$ & $-0,03$ \\
\hline & Pau-alho & 0,00 & 0,04 & $-0,02$ & $-0,02$ & $-0,03$ & $-0,03$ & 0,00 & $-0,02$ & $-0,03$ & $-0,04$ \\
\hline & Pau-andrade & 0,00 & 0,00 & 0,00 & $-0,01$ & 0,00 & 0,00 & 0,00 & 0,00 & 0,00 & 0,00 \\
\hline & Médio & 0,00 & 0,61 & 0,05 & $-0,14$ & $-0,12$ & $-0,17$ & 0,00 & $-0,09$ & 0,07 & $-0,28$ \\
\hline \multirow{9}{*}{$\begin{array}{l}\text { ICA Volume } \\
\left(\mathrm{m}^{3} / \text { ha/ano }\right)\end{array}$} & Canela-amarela & 0,00 & $-0,65$ & $-0,45$ & $-0,68$ & $-0,84$ & $-1,07$ & $-0,66$ & $-1,10$ & $-1,62$ & 0,44 \\
\hline & Canela-coqueiro & 0,00 & $-0,34$ & $-0,01$ & $-0,08$ & 0,06 & $-0,20$ & $-0,52$ & 5,77 & $-0,19$ & 0,38 \\
\hline & Canela-guaicá & 0,00 & 10,93 & 1,00 & $-0,64$ & $-0,40$ & $-0,61$ & $-0,40$ & $-0,42$ & $-0,68$ & $-0,54$ \\
\hline & Canela-imbuia & 0,00 & 0,73 & $-0,18$ & $-0,07$ & 0,32 & $-0,22$ & 1,08 & $-0,24$ & $-0,46$ & $-0,16$ \\
\hline & Canela-sebo & 0,00 & 0,29 & $-0,11$ & $-0,12$ & $-0,11$ & 0,27 & $-0,08$ & 1,02 & $-0,22$ & $-0,09$ \\
\hline & Imbuia & 0,00 & $-1,19$ & 1,19 & $-0,12$ & $-0,19$ & $-0,37$ & $-1,09$ & $-0,16$ & $-0,62$ & 0,19 \\
\hline & Pau-alho & 0,00 & 0,74 & $-0,23$ & $-0,19$ & $-0,36$ & $-0,36$ & $-0,20$ & $-0,43$ & $-0,39$ & $-0,24$ \\
\hline & Pau-andrade & 0,00 & $-0,04$ & 0,00 & $-0,08$ & 0,00 & $-0,01$ & $-0,01$ & $-0,01$ & $-0,01$ & $-0,01$ \\
\hline & Médio & 0,00 & 10,47 & 1,21 & $-1,98$ & $-1,53$ & $-2,57$ & $-1,88$ & 4,43 & $-4,20$ & $-0,03$ \\
\hline
\end{tabular}




\section{CONCLUSÕES}

As conclusões desta pesquisa foram as seguintes:

Em 10 anos de dinâmica estrutural, a família Lauraceae, de maneira geral, vem mantendo praticamente inalterada sua posição de importância na comunidade.

A comunidade de Lauraceae passa por aumento de densidade, crescendo em abundância na floresta, em razão do recrutamento ser maior que a mortalidade.

Ocorre uma redução da área basal, DAP médio e volume por causa da mortalidade, que ainda que não seja alta em termos de indivíduos, deu-se em função da morte dos maiores indivíduos.

Os incrementos dimensionais dessa comunidade vegetal tem sido muito baixos nesses últimos 10 anos, tanto em diâmetro das árvores, como em área basal e volume.

Embora a maior parte das Lauráceas apresente um padrão dinâmico lento, algumas espécies estão passando por um intenso processo de mudanças, como é o caso da Nectandra grandiflora (canela-amarela), que incrementou sua posição na maioria dos indicadores estruturais e dinâmicos, constituindo-se na espécie de maior destaque entre todas as analisadas.

A Nectandra grandiflora (canela-amarela) apresenta recrutamento muito superior à mortalidade, distribuição diamétrica decrescente e ampla distribuição espacial. Esses elementos estão tornando essa espécie uma das três mais importantes em toda a comunidade, juntamente com a araucária e a erva-mate (Ilex paraguariensis A.St.-Hil.).

Em 10 anos, as mudanças estruturais na floresta parecem sutis, mas, observando detalhadamente cada população, é possível distinguir características sutis das espécies. Por isso, é importante proceder às análises estruturais e dinâmicas de forma detalhada para cada população;

As informações reportadas neste artigo podem servir como indicativos a serem utilizados em Planos de Manejo para as Lauráceas em Florestas de Araucária semelhantes.

\section{REFERÊNCIAS BIBLIOGRÁFICAS}

BARROS, P. L. C. Estudo fitossociológico de uma floresta tropical úmida no planalto de Curuá : uma Amazônia brasileira. 1986. 147f. Tese (Doutorado em Engenharia Florestal) - Universidade Federal do Paraná, Curitiba, 1986.

BITTENCOURT, S.; DALlA CORTE, A P.; SANQUETTA, C.R. Estrutura da comunidade de Pteridophyta em uma floresta ombrófila mista, sul do Paraná, Brasil. Silva Lusitana, v. 12, n. 2, p. 243-254, 2004.

INSTITUTO BRASILEIRO DE GEOGRAFIA E ESTATÍSTICA. Manual técnico da vegetação brasileira. Rio de Janeiro: IBGE, 1990.92p.

LONGHI, S. J. A estrutura de uma floresta natural de Araucaria angustifolia (Bertol.) Kuntze, no sul do Brasil. 1980. 198f. Dissertação (Mestrado em Engenharia Florestal) - Universidade Federal do Paraná, Curitiba, 1980.

PIZATTO, W. Avaliação biométrica da estrutura e da dinâmica de uma floresta ombrófila mista em São João do Triunfo-PR: 1995 a 1998. 1999. 172f. Dissertação (Mestrado em Engenharia Florestal) - Universidade Federal do Paraná, Curitiba, 1999.

SANQUETTA, C.R. Os números atuais da cobertura florestal do Paraná. 2004. 6p. Disponível em: $<$ www.ambientebrasil.com.br > Acesso em: 8 jan. 2004.

SANQUeTTA, C.R.; MATTEI, E. Manejo racional da floresta de araucária. Revista Meio Ambiente de Santa Catarina, Florianópolis, v. 2, p. 58, 2002.

SANQUETTA, C. R. ; DALLA CORTE, A. P. ; EISFELD, R. L. Crescimento, mortalidade e recrutamento em duas florestas de araucária (Araucaria angustifolia (Bertol.) Kuntze) no Estado do Paraná, Brasil. Revista Ciências Exatas e Naturais, v. 5, n.1, p. 101-112, 2003.

SEeliger, U; CORDAZZO, C.; BARbosa, F. Os sites e o Programa Brasileiro de Pesquisas Ecológicas de Longa Duração. Belo Horizonte: FURGS/UFMG, 2002. 187p.

SCOLFORO, J. R. Manejo florestal. Lavras: UFLA/FAEPE, 1998. p. 225-229. 